\title{
Carotid plaque score and intima media thickness as predictors of stroke and mortality in hypertensive patients
}

\author{
Tatsuo Kawai, Mitsuru Ohishi, Yasushi Takeya, Miyuki Onishi, Norihisa Ito, Ryosuke Oguro, \\ Koichi Yamamoto, Kei Kamide and Hiromi Rakugi
}

The mean intima media thickness (IMT) and plaque score from carotid ultrasonography are both widely used to evaluate macrovascular atherosclerotic change. The present study sought to examine which parameter more effectively predicts patient prognosis. This hospital-based cohort study included 356 patients with essential hypertension (mean age: $62.4 \pm 0.6$ ). We investigated how the mean IMT and plaque score correlated with various parameters, including pulse wave velocity (PWV), and we assessed the ability of the mean IMT and plaque score to predict cardiovascular events and total mortality. The mean IMT and plaque score significantly correlated with systemic atherosclerotic change, target organ damage, age and PWV. Subjects with a higher mean IMT and subjects with higher plaque scores showed higher frequencies of stroke and total mortality. In addition, subjects with marginal thickening of the intima media (mean $\geqslant 0.7$ ) showed a significantly higher frequency of stroke than subjects with a mean IMT of $<0.7$. After adjustment for traditional risk factors, plaque score was significantly and independently predictive of stroke, and the predictive ability of the plaque score for the onset of stroke was equivalent to that of PWV. The mean IMT and plaque score showed a nonsignificant trend of higher risk of mortality after adjustment for traditional risk factors. The mean IMT and plaque score were significantly correlated with systemic atherosclerotic change. We revealed that plaque score predicted the onset of stroke more accurately than the mean IMT, and the accuracy of this prediction was equivalent to that from PWV in hypertensive patients. We also showed that marginal thickening of the intima media (as measured by mean IMT) may be a predictor of stroke.

Hypertension Research (2013) 36, 902-909; doi:10.1038/hr.2013.61; published online 4 July 2013

Keywords: cardiovascular disease; carotid ultrasonography; intima media thickness; plaque score; prognosis

\section{INTRODUCTION}

Hypertension is one of the strongest and most prevalent risk factors for cardiovascular diseases (CVDs), ${ }^{1,2}$ including stroke ${ }^{3}$ and ischemic heart disease. ${ }^{4}$ To prevent these conditions, we must assess systemic atherosclerotic change during hypertension management. Many methods have been reported to be useful for assessing arterial functions. For example, the presence of proteinuria or fundic sclerotic change have been reported to reflect microvascular atherosclerosis. Similarly, the resistive index has been reported to reflect vascular resistance; ${ }^{5}$ reactive hyperemia has been reported to reflect endothelial function; ${ }^{6}$ and pulse wave velocity (PWV) has been reported to reflect arterial stiffness. ${ }^{7}$

Carotid ultrasonography is a simple and noninvasive method that is extensively used for evaluating atherosclerotic change ${ }^{8}$ and is a well-studied method for detecting macrovascular atherosclerosis. ${ }^{9}$ Mean intima media thickness (IMT) has been shown to be strongly associated with CVD and has become the most common marker evaluated by carotid ultrasonography. ${ }^{10,11}$ However, several investigators have suggested that IMT cannot qualitatively evaluate atherosclerotic changes, for example, lesions with a necrotic core, and that other parameters should be used to more precisely estimate the atherosclerotic state. ${ }^{12}$ Studies have also indicated that plaque score is correlated with CVD. ${ }^{13,14}$ A review suggested that plaque score could predict coronary heart disease and might be more representative of atherosclerosis than mean IMT. ${ }^{15}$ Furthermore, Ershova et al. ${ }^{16}$ reported that plaque number, plaque score and markers of percent area of stenosis were more sensitive than mean IMT for cardiovascular risk estimation in patients with familial hypercholesterolemia.

However, it has not been clearly demonstrated which parameter in carotid ultrasonography can best predict patient prognosis in relation to stroke, coronary heart disease and mortality among hypertensive patients. Previously, we reported that increased aortic stiffness evaluated by carotid-femoral PWV (cfPWV) is more prognostic of 
cardiovascular events among hypertensive patients than several noninvasive atherosclerotic evaluations in a hospital-based cohort study. ${ }^{17}$ In the current study, we conducted sub-analyses of the same cohort as studied in our previous study ${ }^{17}$ and investigated whether mean IMT and plaque score correlated differently with various parameters, including PWV. We also assessed the hypothesis that plaque score was the more sensitive surrogate marker for systemic atherosclerotic change and could more accurately predict cardiovascular events among hypertensive patients. Furthermore, we assessed the correlation between marginal thickening of the intima media (as determined by mean IMT) and the onset of cardiovascular events.

\section{METHODS}

\section{Study subjects and study design}

This hospital-based cohort study was part of the Non-Invasive Atherosclerotic Evaluation in Hypertension (NOAH) study, ${ }^{17}$ in which a total of 813 serial outpatients who had been diagnosed with essential hypertension were sequentially recruited between January 1998 and June 2004 at Osaka University Medical Hospital. A total of 356 serial outpatients who had been diagnosed with essential hypertension and had undergone carotid Doppler ultrasonography were sequentially recruited in this study. Patients showing arterial fibrillation or having malignant diseases were excluded. The study protocol was approved by the hospital ethics committee, and written informed consent was obtained from all participants.

\section{Follow-up evaluation}

Clinical follow-up was conducted by clinical visits, mailed questionnaires and telephone contact every September starting in 2003. As we could not contact several subjects or their relatives, the follow-up rate of the NOAH study cohort was $94.3 \%$.

The questionnaire included events related to hypertensive complications and cause of death. Patient responses were confirmed by checking the responses against patient medical sheets. The primary end points were the following: new onset of stroke (paralysis and diagnosis with CT and/or MRI); new onset of CVD, including angina pectoris (typical chest pain with ST segment changes on electrocardiograms); myocardial infarction (ST segmental elevation and $>2$-fold creatinine kinase elevation); heart failure (diagnosed using American Heart Association criteria); or rupture of an aortic aneurysm (diagnosed by ultrasound echography or CT). The average follow-up duration was $6.4 \pm 0.2$ years, which was measured as the interval from the initial evaluation to event onset or September 2010.

\section{Blood pressure Measurements}

Conventional blood pressure measurements were made by trained observers with an electronic sphygmomanometer (HEM-705IT or HEM-711, OMRON). Following the guidelines for hypertension management, clinic blood pressure was measured at least twice in the sitting position after a 5-min rest. If the difference between the readings was $<5 \mathrm{mmHg}$, the average of the two readings was recorded. If the difference was $>5 \mathrm{~mm} \mathrm{Hg}$, additional measurements were performed to obtain stable readings, and the average of two stable readings was recorded.

\section{Renal function}

Estimated glomerular filtration rate (eGFR) was calculated using the following equation:

eGFR $\left(\mathrm{ml} \mathrm{min}^{-1} 1.73 \mathrm{~m}^{-2}\right)=194 \times$ creatinine $(-1.094) \times \operatorname{age}(-0.287)$ $(\times 0.739$ if female $){ }^{18}$

\section{Ultrasonographic determination}

A trained technician examined the echocardiograms and carotid ultrasonograms (Power Vision 6000; Toshiba, Tokyo, Japan) and used the mean of three examinations as a representative measurement. Plaque score and the mean IMT of the carotid artery were determined by carotid ultrasonography as previously reported; ${ }^{19}$ to obtain the plaque score, protruding lesions with an IMT $\geqslant 1.1 \mathrm{~mm}$ were defined as atheromatous plaque. Plaque score was calculated by summing all the plaque thickness measurements in both carotid arteries (S1 to S4).

\section{Target organ damage and associated clinical conditions}

We evaluated target organ damage (TOD) and associated clinical conditions according to the 2007 guidelines for arterial hypertension management from the European Society of Hypertension and the European Society of Cardiology. ${ }^{20}$ Cerebrovascular disease was assessed by brain MRI, CT and neurological findings. Coronary artery disease was assessed by ECG, echocardiogram and typical symptoms. Lacunar infarcts were evaluated by brain MRI. Patients with diabetes mellitus were diagnosed according to the following diagnosis criteria of the American Diabetes Association: fasting plasma glucose at or above $126 \mathrm{mg} \mathrm{dl}^{-1}, \mathrm{HbAlc} \geqslant 6.5 \%$, a 2 -h value in an oral glucose tolerance test at or above $200 \mathrm{mg} \mathrm{dl}^{-1}$, a random plasma glucose concentration $\geqslant 200 \mathrm{mg} \mathrm{dl}^{-1}$ in the presence of symptoms, or if the patient was taking drugs for diabetes. Patients were diagnosed with hyperlipidemia under the following conditions: total cholesterol $\geqslant 220 \mathrm{mg} \mathrm{dl}^{-1}$, low-density lipoprotein cholesterol $\geqslant 140 \mathrm{mg} \mathrm{dl}^{-1}$, triglycerides $\geqslant 150 \mathrm{mg} \mathrm{dl}^{-1}$, or if the patient was taking drugs for hyperlipidemia.

\section{PWV measurement}

We assessed cfPWV as a representative PWV to evaluate arterial stiffness. For the PWV measurements, participants visited the hospital in the morning and were instructed not to take any antihypertensive drugs, nitrate or aspirin for $8 \mathrm{~h}$ preceding their visit. Measurements were performed in a controlled environment at $22 \pm 2{ }^{\circ} \mathrm{C}$ with each patient in the supine position after 30 min of rest: a model FCP-4731 pulsimeter (Fukuda Denshi, Tokyo, Japan) that allowed on-line pulse wave recording and automatic calculation was used in accordance with a previously reported method. ${ }^{21}$ Three measurements were taken at intervals of $2 \mathrm{~min}$ and averaged. The intra-observer coefficient of variation was $2.8 \pm 1.2 \%$, which was calculated using three measurements each from seven healthy men.

\section{Statistical analysis}

Data were analyzed using JMP ver. 9.0.1 (SAS, Cary, NC, USA) and are presented as the mean \pm s.e.m. An event-free curve was estimated using the Kaplan-Meier method. The Wilcoxon test was used to compare differences in event-free rates between groups of subjects with different IMT and plaque scores. A Cox proportional hazards model was used to detect the relative risks of IMT and plaque score on the prognoses. Analysis of variance and Student's $t$-test were used to test for significant differences among groups of patients with different mean IMT or plaque scores. A $P$-value $<0.05$ was considered significant.

\section{RESULTS}

During a mean follow-up period of $6.4 \pm 0.2$ years, 37 individuals had a stroke, 24 individuals developed CVD and 37 individuals died. Table 1 shows the baseline clinical characteristics of the patients. First, we divided our subjects into three groups according to the level of the mean $\mathrm{IMT}(\mathrm{IMT} \geqslant 1.0, n=85 ; 1.0>\mathrm{IMT} \geqslant 0.7, n=168$; $\mathrm{IMT}<0.7$, $n=103$ ) and compared the characteristics among these three groups. Subjects with a higher mean IMT showed significantly a higher maleto-female ratio, age, prevalence of diabetes mellitus, plaque score, smoking index, and pulse pressure, and they showed a significantly lower eGFR and high-density lipoprotein cholesterol level (Table 1). We also divided the subjects into three groups according to the plaque score (plaque score $=0, n=171 ; 0<$ plaque score $<5, n=116$; plaque score $\geqslant 5, n=69)$ and compared the characteristics among these three groups. Subjects with a higher plaque score showed a significantly higher age, IMT, ratio of current smoking, smoking index, systolic blood pressure, pulse pressure and uric acid, and they showed a significantly lower eGFR (Table 1). 
Table 1 Baseline clinical characteristics of the study population and comparison of baseline characteristics among groups with different mean IMT/ plaque score

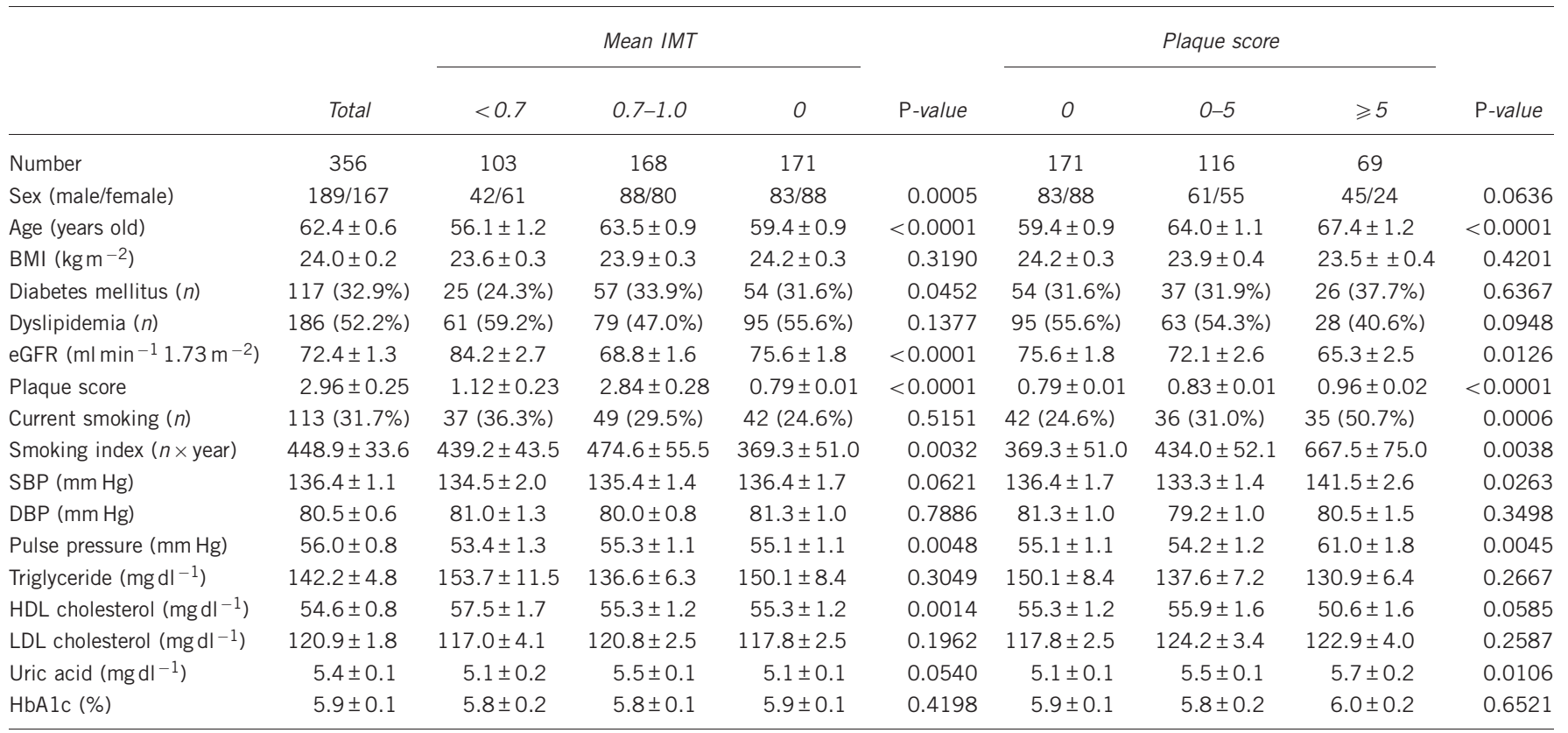

Abbreviations: BMI, body mass index; DBP, diastolic blood pressure; HDL, high-density lipoprotein; IMT, intima media thickness; LDL, low-density lipoprotein; SBP, systolic blood pressure. Values are expressed as mean \pm s.e.m. or numbers.

Next, to investigate the relationship of the mean IMT and plaque score with TOD, we divided our subjects into three groups according to the level of TOD and compared the mean IMT and plaque score among these three groups. Subjects with associated clinical conditions $(0.916 \pm 0.020)$ showed a significantly higher IMT than subjects with TOD $(0.860 \pm 0.012 ; \quad P=0.0058)$ and subjects without TOD $(0.683 \pm 0.009 ; \quad P<0.0001)$. Subjects with TOD also showed a significantly higher IMT than subjects without TOD $(P<0.0001)$. Similarly, the plaque scores of the subjects with associated clinical conditions $(5.787 \pm 0.688)$ were significantly higher than those of either the subjects with TOD $(2.728 \pm 0.290 ; P=0.0002)$ or the subjects without TOD $(0.568 \pm 0.132 ; P<0.0001)$. Subjects with TOD also showed significantly higher plaque scores than subjects without TOD $(P<0.0001)$ (Figure 1a).

To assess the relationship of the IMT and plaque score with cardiac atherosclerotic change and microvascular atherosclerotic change, we compared the IMT and plaque score of subjects with and without left ventricular hypertrophy and subjects with and without proteinuria. Subjects with left ventricular hypertrophy showed a significantly higher IMT $(0.873 \pm 0.021$ vs. $0.819 \pm 0.011 ; P=0.0119)$ and higher plaque scores $(4.334 \pm 0.680$ vs. $2.613 \pm 0.248 ; P=0.0305)$ than subjects without left ventricular hypertrophy. Subjects with proteinuria also showed a significantly higher IMT $(0.872 \pm 0.023$ vs. $0.823 \pm 0.010 ; P=0.0305)$ and higher plaque scores $(4.276 \pm 0.729$ vs. $2.774 \pm 0.264 ; P=0.0279)$ than subjects without proteinuria (Figure 1b). We also investigated the relationship of the IMT and plaque score with arterial stiffness evaluated by PWV, and we showed that both the IMT $\left(R^{2}=0.1032, P<0.0001\right)$ and plaque score $\left(R^{2}=0.2012, P<0.0001\right)$ were significantly correlated with $\mathrm{PWV}$ (Figure 2$)$. In addition, both the IMT $\left(R^{2}=0.1612, \mathrm{P}<0.0001\right)$ and plaque score $\left(R^{2}=0.0612, \mathrm{P}<0.0001\right)$ were significantly correlated with age (Figure 2).

Kaplan-Meier analysis revealed that subjects with a higher mean IMT and plaque score showed a higher frequency of stroke
( $P=0.0398$ and $P=0.0005$, respectively). The rates of coronary heart disease did not significantly differ between subjects with a higher IMT and those with a lower IMT $(P=0.6696)$ or between subjects in different plaque score groups $(P=0.6449)$. Subjects with a higher mean IMT and plaque score showed higher mortality rates ( $P=0.0299$ and $P=0.0005$, respectively) (Figure 3a). Notably, subjects with a mean IMT of $\geqslant 0.7$ showed a significantly higher frequency of stroke than subjects with a mean IMT $<0.7$, although subjects with a mean IMT value of $\geqslant 1.0$ did not show a different frequency of stroke from subjects with a mean IMT $<1.0$ (Figure $3 b$ ). Subjects who experienced a stroke showed a significantly higher age, plaque score, mean IMT, systolic blood pressure (SBP) and diastolic blood pressure, and showed a significantly lower eGFR than subjects who did not experience a stroke (Table 2). Subjects who died in the follow-up period showed a significantly higher male-to-female ratio, age, plaque score, mean IMT, smoking index and pulse pressure, and they showed a significantly lower BMI and eGFR than subjects who did not die in the follow-up period (Table 2).

Finally, we examined whether the IMT and plaque score could predict the onset of stroke or mortality and whether this prediction was independent of other traditional risk factors (age, sex, diabetes mellitus and dyslipidemia) and systolic blood pressure. The Cox proportional hazards model with the end point of stroke indicated that plaque score was significantly and independently predictive of stroke. In contrast, the Cox proportional hazards model with the end point of death indicated that the IMT and plaque score showed only nonsignificant trends of higher risk of mortality after adjustment for traditional risk factors and SBP (Table 3). Additionally, to compare the predictive ability of the IMT or plaque score with that of PWV, which is well known to be correlated with the onset of cardiovascular events, we classified our subjects into three groups according to their tertile of cfPWV. The Cox proportional hazards model with the end point of stroke showed that after adjustment for traditional risk factors and SBP, the relative risk among the first tertile of cfPWV 
a

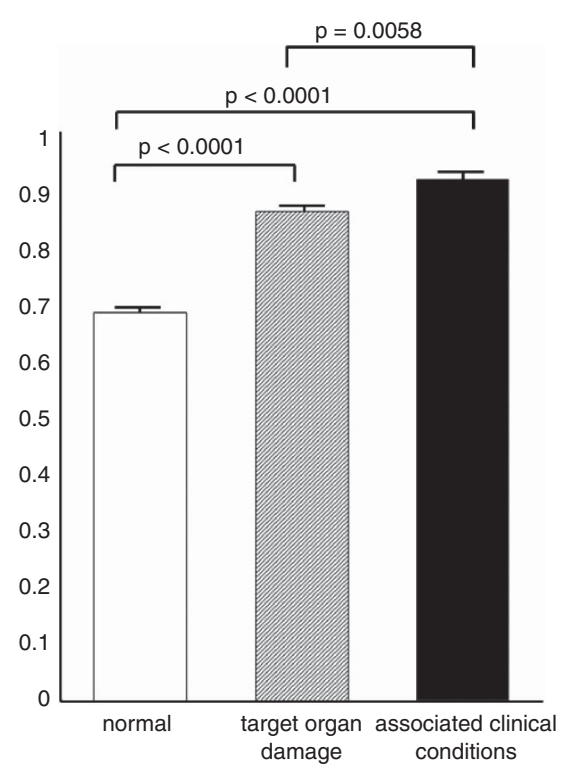

b

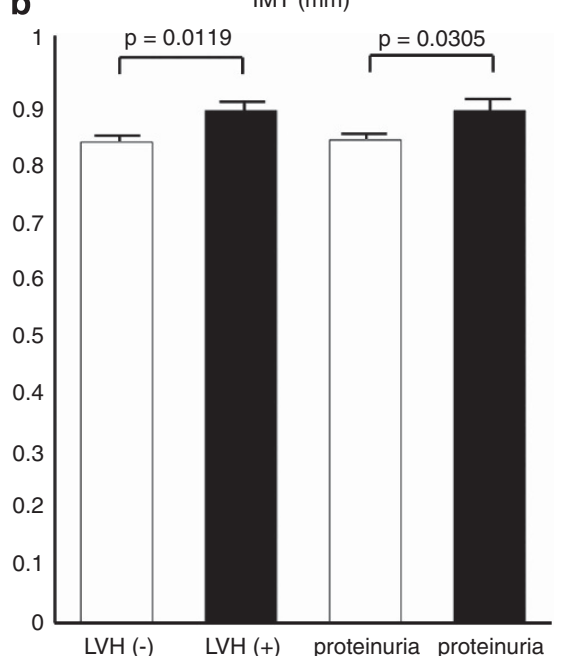

$(-)$

$(+)$
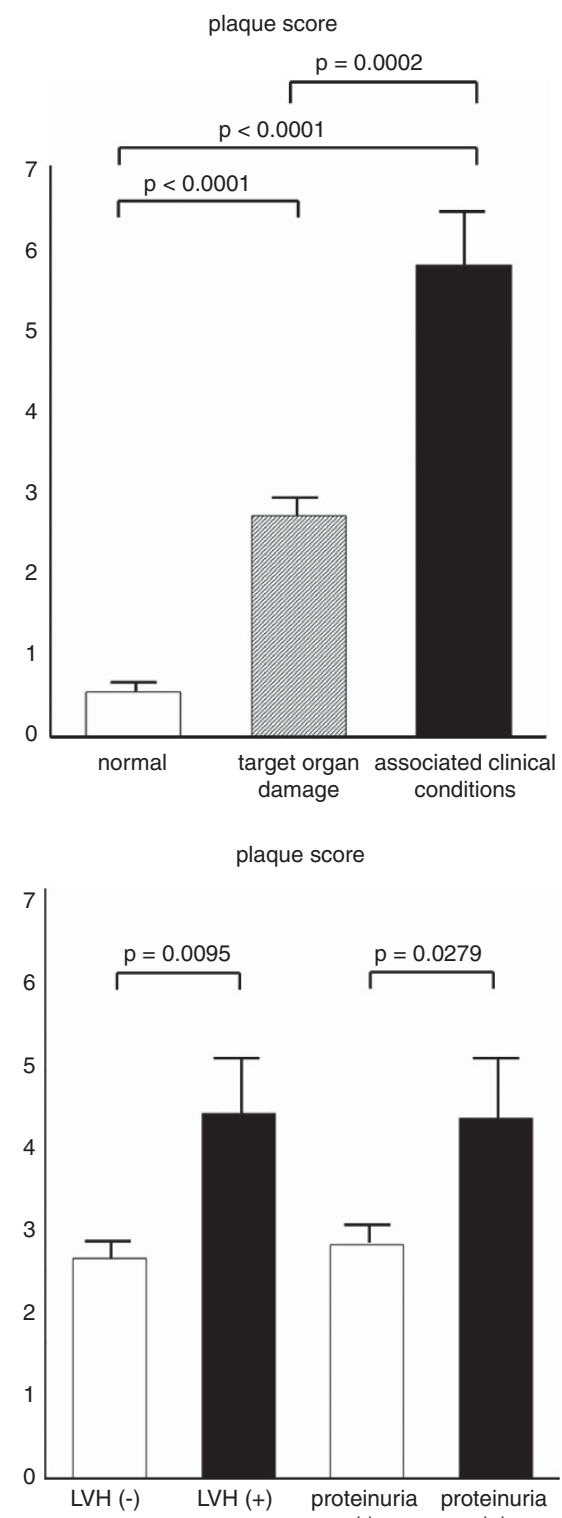

$(+)$

Figure 1 (a) Comparisons of the IMT (left) and the plaque score (right) among subjects without target organ damage (TOD), with TOD, and with associated clinical conditions. (b) Comparisons of the IMT (left) and the plaque score (right) between subjects with and without left ventricular hypertrophy, and between subjects with and without proteinuria.

compared with the third tertile of cfPWV was $3.24(P=0.0238)$, and the relative risk among the second tertile of cfPWV compared with the third tertile of cfPWV was $1.81(P=0.2722)$. Similarly, the Cox proportional hazards model with the end point of death showed that after adjustment for traditional risk factors and SBP, the relative risk among the first tertile of $\mathrm{cfPWV}$ compared with the third tertile of cfPWV was $15.18(P=0.0001)$, and the relative risk among the second tertile of cfPWV compared with the third tertile of cfPWV was $5.33(P=0.0569)$.

\section{DISCUSSION}

The mean IMT and plaque score have both been widely used as surrogate markers for systemic atherosclerotic change. In this study, we showed that both markers were strongly correlated with each other (as previously reported) and were significantly positively correlated with age, smoking index, pulse pressure, TOD, left ventricular mass index and proteinuria and that they were negatively correlated with eGFR. We also showed that the subjects who experienced a stroke or who died in the follow-up period had a higher plaque score and mean IMT. We also revealed differences between the IMT and plaque scores concerning the correlations with systemic atherosclerotic change and prognosis.

IMT and plaque score are well known to reflect macrovascular atherosclerosis, ${ }^{9}$ and PWV is well known to reflect arterial stiffness. ${ }^{7}$ Although these parameters are widely used as surrogate markers for CVDs, there have been no studies, to our knowledge, that compare the predictive ability for cardiovascular events among IMT, plaque score and PWV. We compared the predictive ability of IMT or plaque 

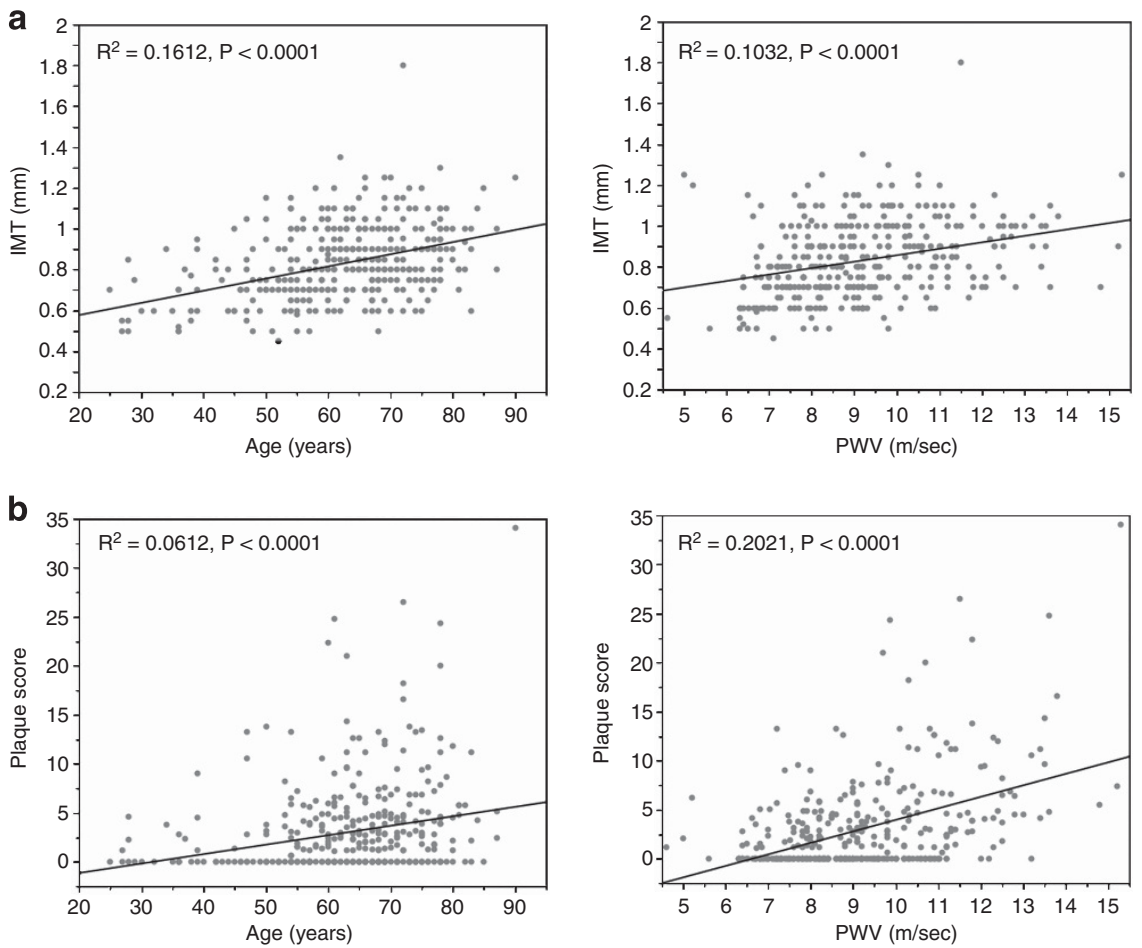

Figure 2 (a) Scatter plots and regression graphs showing significant correlations of the IMT with age (left) and with PWV (right). (b) Scatter plots and regression graphs showing significant correlations of the plaque score with age (left) and with PWV (right).

score with that of PWV for the onset of stroke and total mortality in the present cohort. We showed that the relative risk of stroke that was predicted by plaque score was equivalent to that predicted by PWV, which was previously reported to be an independent predictor of all CVD including stroke. ${ }^{17}$ This result indicated that plaque score could predict the onset of stroke as well as PWV, although PWV could predict death more accurately than plaque score or IMT.

As many study subjects were already receiving medical treatment for hypertension, we could not show significant correlations of SBP and diastolic blood pressure with other parameters; however, pulse pressure was significantly correlated with the mean IMT and plaque score. Pulse pressure reportedly rises as the aorta stiffens with aging or atherosclerotic disease progression. ${ }^{22,23}$ Increased pulse pressure is also reportedly associated with CVD. ${ }^{24-26}$ Our results revealed that both the plaque score and the mean IMT were significantly correlated with the PWV; additionally, the coefficient of determination between the PWV and the plaque score was larger than that between the PWV and the mean IMT (0.2021 vs. 0.1032). As PWV represents arterial stiffness, ${ }^{27}$ our result suggests that plaque score reflects increased arterial stiffness more strongly than mean IMT.

It is controversial as to which index, the mean IMT or the plaque score, predicts stroke more accurately. Previous analyses of subjects with various conditions have shown plaque score ${ }^{28}$ and $\mathrm{IMT}^{29}$ to be more significantly correlated with abnormal cerebral findings evaluated by brain MRI. Lee et al. ${ }^{30}$ reported that both the IMT and the plaque score were associated with acute ischemic stroke in patients with type 2 diabetes. In the present study, both the mean IMT and the plaque score were significantly correlated with the onset of stroke. We also showed that the plaque score, but not the mean IMT, was significantly correlated with the onset of stroke even after adjustment for other traditional risk factors, indicating that the plaque score could be a more effective marker than the mean IMT for predicting stroke in patients with essential hypertension. Stroke is influenced by the duration and severity of pressure overload caused by longitudinal increase in blood pressure, ${ }^{31}$ which are factors that are also predicted by $\mathrm{PWV}^{27}$ Hence, the stronger correlation between plaque score and PWV might explain why plaque score more accurately predicted stroke onset.

Notably, subjects with a mean IMT of $\geqslant 0.7$ showed significantly higher frequency of stroke than subjects with a mean IMT of $<0.7$; however, subjects with a mean IMT of $\geqslant 1.0$ did not show a difference in their frequency of stroke compared with subjects with a mean IMT of $<1.0$. IMT reflects adaptive arterial wall changes in response to shear stress. Previous studies indicated that the IMT is mainly correlated with hypertension, ${ }^{32}$ thus the mean IMT in hypertensive patients is thought to be influenced by routine high blood pressure. Therefore, unlike in cases of other subjects with high cardiovascular risk (for example, those with diabetes and hypercholesterolemia), marginal thickening of the mean IMT could predict CVD in hypertensive patients. However, because only 24 of our subjects developed coronary heart disease, we did not show a significant correlation between coronary heart disease and either the mean IMT or the plaque score, although such correlations were reported in previous studies. ${ }^{11,33}$

This study has several limitations. First, this cohort study was hospital-based and included a relatively small number of patients. In addition, because the present study was conducted at a university medical hospital that specializes in hypertensive treatment and serves many high-risk patients who are referred to the hospital from general physicians, our study cohort consisted of high-risk patients. We think this is the reason why the event rate in this study was high $(\sim 4 \%$ per year) compared with other cohort studies such as the candesartan antihypertensive survival evaluation in Japan (CASE-J) trial $^{34}$ or a 

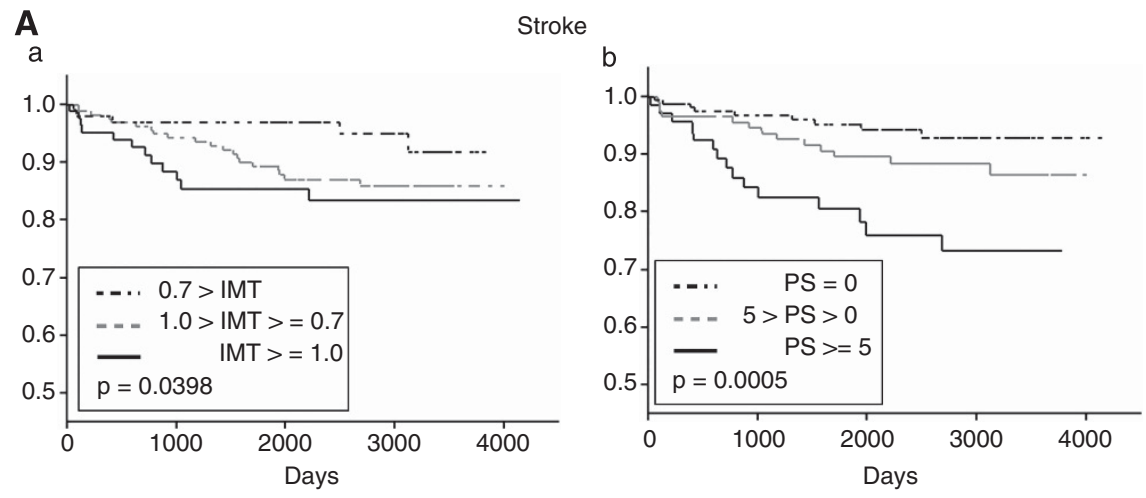

Coronary heart disease
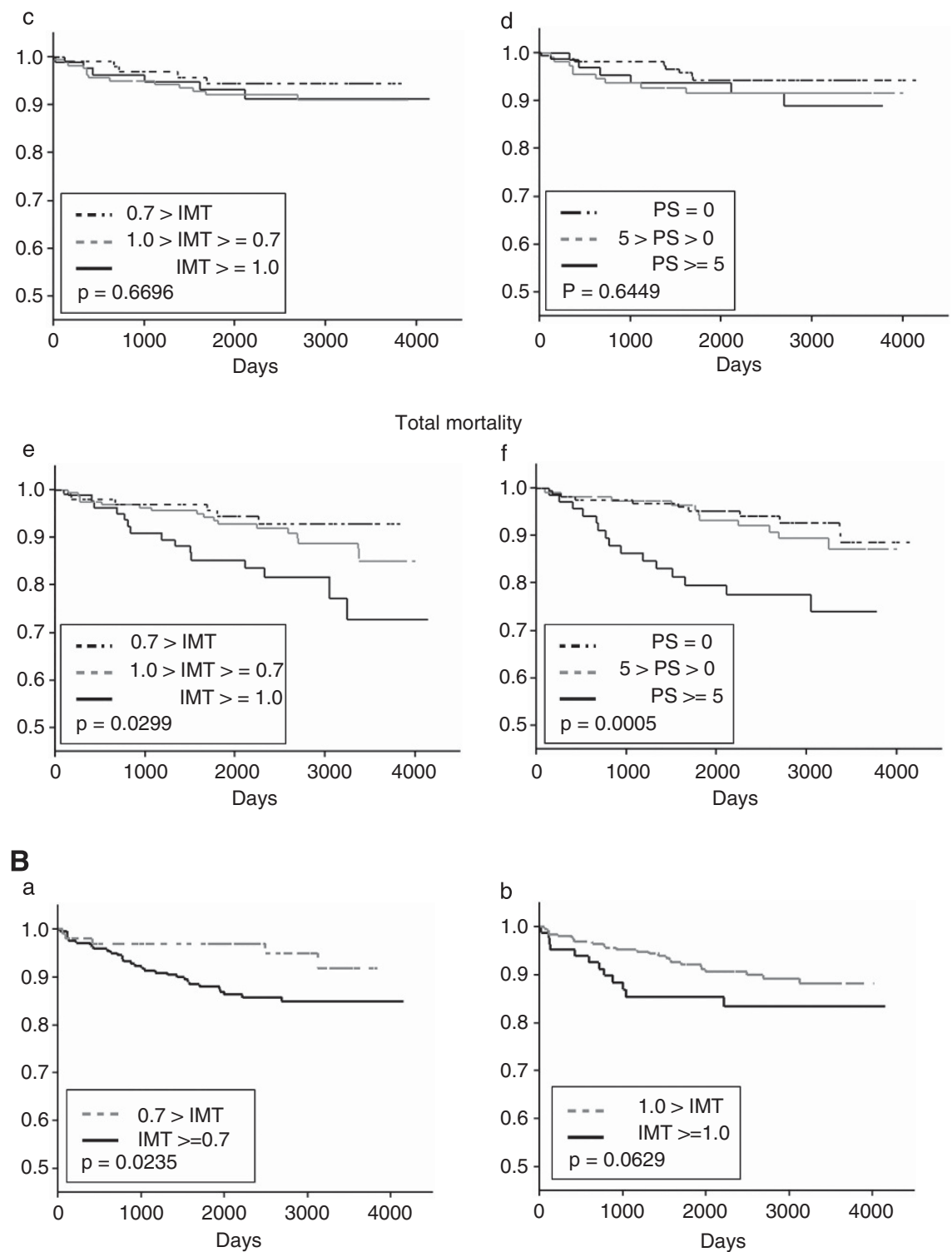

Figure 3 (A) Kaplan-Meier analysis. Subjects with a higher mean IMT (a) and a higher plaque score (b) showed significantly higher incidences of stroke. There were no significant differences in the incidence of coronary heart disease among subjects in different mean IMT groups (c) or in different plaque score groups (d). Subjects with a higher mean IMT (e) or a higher plaque score (f) showed significantly higher mortality rates. (B) Kaplan-Meier analysis for stroke. (a) Subjects with a higher IMT (IMT $\geqslant 0.7$ ) showed a significantly higher incidence of stroke. (b) There were no significant differences in the incidence of coronary heart disease between subjects with a higher IMT and those with a lower mean IMT. 
Table 2 Comparison of baseline characteristics between the subjects with or without the episode of stroke and death

\begin{tabular}{|c|c|c|c|c|c|c|}
\hline & \multicolumn{2}{|c|}{ Stroke } & \multirow[b]{2}{*}{ P-value } & \multicolumn{2}{|c|}{ Death } & \multirow[b]{2}{*}{ P-value } \\
\hline & + & - & & + & - & \\
\hline Sex (male/female) & $21 / 16$ & $168 / 151$ & 0.6368 & $27 / 10$ & $162 / 157$ & 0.0105 \\
\hline Age (years old) & $66.5 \pm 1.7$ & $62.0 \pm 0.7$ & 0.0089 & $71.0 \pm 1.7$ & $61.4 \pm 0.7$ & $<0.0001$ \\
\hline $\mathrm{BMI}\left(\mathrm{kgm}^{-2}\right)$ & $24.2 \pm 0.5$ & $23.9 \pm 0.2$ & 0.6162 & $22.6 \pm 0.5$ & $24.1 \pm 0.2$ & 0.0086 \\
\hline eGFR $\left(\mathrm{ml} \mathrm{min}^{-1} 1.73 \mathrm{~m}^{-2}\right)$ & $67.6 \pm 2.8$ & $73.0 \pm 1.4$ & 0.0441 & $58.7 \pm 4.8$ & $74.0 \pm 1.3$ & 0.0018 \\
\hline plaque score & $5.18 \pm 1.03$ & $2.70 \pm 0.25$ & 0.0124 & $6.72 \pm 1.38$ & $2.53 \pm 0.22$ & 0.0023 \\
\hline Mean IMT (mm) & $0.91 \pm 0.03$ & $0.82 \pm 0.01$ & 0.0100 & $0.93 \pm 0.04$ & $0.82 \pm 0.01$ & 0.0026 \\
\hline current smoking $(n)$ & $9(24.3 \%)$ & $104(33.1 \%)$ & 0.2787 & $15(41.7 \%)$ & $98(31.1 \%)$ & 0.1991 \\
\hline smoking index ( $n \times$ year) & $459.2 \pm 106.1$ & $447.7 \pm 35.5$ & 0.4592 & $712.3 \pm 113.3$ & $418.0 \pm 34.7$ & 0.0085 \\
\hline $\mathrm{SBP}(\mathrm{mm} \mathrm{Hg})$ & $141.4 \pm 2.7$ & $135.8 \pm 1.1$ & 0.0310 & $140.8 \pm 4.0$ & $135.9 \pm 1.1$ & 0.1233 \\
\hline LDL cholesterol $\left(\mathrm{mg} \mathrm{dl}^{-1}\right)$ & $120.2 \pm 5.5$ & $121.0 \pm 1.9$ & 0.5574 & $113.2 \pm 6.5$ & $121.7 \pm 1.9$ & 0.8929 \\
\hline Uric acid $\left(\mathrm{mg} \mathrm{dl}^{-1}\right)$ & $5.6 \pm 0.3$ & $5.3 \pm 0.1$ & 0.1682 & $5.7 \pm 0.2$ & $5.3 \pm 0.1$ & 0.0694 \\
\hline HbAlc (\%) & $5.6 \pm 0.2$ & $5.9 \pm 0.1$ & 0.2352 & $5.7 \pm 0.2$ & $5.9 \pm 0.1$ & 0.5525 \\
\hline
\end{tabular}

Values are expressed as mean \pm SEM or numbers.

Table 3 Cox proportional hazard model

\begin{tabular}{|c|c|c|c|c|c|c|}
\hline End point: stroke & & $R R$ & P-value & & $R R$ & P-value \\
\hline Not adjusted & $0.7-1.0 /<0.7$ & 2.42 & 0.055 & $0-5 / 0$ & 1.99 & 0.109 \\
\hline \multirow[t]{2}{*}{ Adjusted for age, sex, DM, HL } & $\geqslant 1.0 /<0.7$ & 2.57 & 0.083 & $\geqslant 5-0$ & 4.12 & 0.001 \\
\hline & $0.7-1.0 /<0.7$ & 2.12 & 0.121 & $0-5 / 0$ & 1.75 & 0.202 \\
\hline \multirow[t]{2}{*}{ End point: death } & \multicolumn{3}{|c|}{$\operatorname{IMT}(\geqslant 1.0 / 0.7-1.0 / 0.7>)$} & \multicolumn{3}{|c|}{ Plaque score $(\geqslant 5 / 0-5 / 0)$} \\
\hline & & $R R$ & P-value & & $R R$ & P-value \\
\hline Not adjusted & $\geqslant 1.0 /<0.7$ & 3.35 & 0.008 & $\geqslant 5 / 0$ & 3.48 & 0.002 \\
\hline Adjusted for age, sex, DM, HL, SBP & $0.7-1.0 /<0.7$ & 1.18 & 0.677 & $0-5 / 0$ & 2.01 & 0.089 \\
\hline
\end{tabular}

Abbreviations: IMT, intima media thickness; SBP, systolic blood pressure.

Japanese trial on the prognostic implication of PWV (J-TOPP). ${ }^{35}$ Therefore, multi-center trials with a larger cohort are needed to confirm the results of our study. Secondly, at enrollment, many subjects had already been treated with various medications, such as angiotensin receptor type II blockers, angiotensin-converting enzyme inhibitors, or statins, which might contribute to better outcomes.

In conclusion, we showed that both the mean IMT and the plaque score were significantly correlated with arterial stiffness and TOD. We also revealed new evidence that the plaque score could more accurately predict the onset of stroke in hypertensive patients, and we also showed that marginal increases in the mean IMT could be a predictor of stroke.

\section{ACKNOWLEDGEMENTS}

This study was funded by the Osaka Medical Research Foundation for Incurable Diseases. 
1 Lloyd-Jones DM, Leip EP, Larson MG, Vasan RS, Levy D. Novel approach to examining first cardiovascular events after hypertension onset. Hypertension 2005; 45: 39-45.

2 Lewington S, Clarke R, Qizilbash N, Peto R, Collins R. Prospective Studies Collaboration.: Age-specific relevance of usual blood pressure to vascular mortality: a meta-analysis of individual data for one million adults in 61 prospective studies. Lancet 2002; 360: 1903-1913.

3 Lawes CM, Vander Hoorn S, Rodgers A. International Society of Hypertension. Global burden of blood-pressure-related disease, 2001. Lancet 2008; 371: 1513-1518.

4 Wilson PW. Established risk factors and coronary artery disease: the Framingham Study. Am J Hypertens 1994; 7: 7S-12S.

5 Florczak E, Januszewicz M, Januszewicz A, Prejbisz A, Kaczmarska M, Michałowska I, Kabat M, Rywik T, Rynkun D, Zieliński T, Kuśmierczyk-Droszcz B, Pregowska-Chwała B, Kowalewski G, Hoffman P. Relationship between renal resistive index and early target organ damage in patients with never treated essential hypertension. Blood Pressure 2009; 18: 55-61.

6 Bonetti PO, Pumper GM, Higano ST, Holmes Jr DR, Kuvin JT, Lerman A. Noninvasive identification of patients with early coronary atherosclerosis by assessment of digital reactive hyperemia. J Am Coll Cardiol 2004; 44: 2137-2141.

7 Cruickshank K, Riste L, Anderson SG, Wright JS, Dunn G, Gosling RG. Aortic pulse-wave velocity and its relationship to mortality in diabetes and glucose intolerance: an integrated index of vascular function? Circulation 2002; 106: 2085-2090.

8 Stein JH, Korcarz CE, Hurst RT, Lonn E, Kendall CB, Mohler ER, Najjar SS, Rembold CM, Post WS. American Society of Echocardiography Carotid Intima-Media Thickness Task Force. Use of carotid ultrasound to identify subclinical vascular disease and evaluate cardiovascular disease risk: a consensus statement from the American Society of Echocardiography Carotid Intima-Media Thickness Task Force. Endorsed by the Society for Vascular Medicine. J Am Soc Echocardiogr 2008; 21: 93-111.

9 Ebrahim S, Papacosta O, Whincup P, Wannamethee G, Walker M, Nicolaides AN, Dhanjil S, Griffin M, Belcaro G, Rumley A, Lowe GD. Carotid plaque, intima media thickness, cardiovascular risk factors, and prevalent cardiovascular disease in men and women: the British Regional Heart Study. Stroke 1999; 30: 841-850.

10 O'Leary DH, Polak JF, Kronmal RA, Manolio TA, Burke GL, Wolfson Jr SK. Carotid-artery intima and media thickness as a risk factor for myocardial infarction and stroke in older adults. Cardiovascular Health Study Collaborative Research Group. N Engl J Med 1999; 340: 14-22.

11 Lorenz MW, Markus HS, Bots ML, Rosvall M, Sitzer M. Prediction of clinical cardiovascular events with carotid intima-media thickness: a systematic review and meta-analysis. Circulation 2007; 115: 459-467.

12 Finn AV, Kolodgie FD, Virmani R. Correlation between carotid intimal/medial thickness and atherosclerosis: a point of view from pathology. Arterioscler Thromb Vasc Biol 2010; 30: 177-181.

13 Chan SY, Mancini GB, Kuramoto L, Schulzer M, Frohlich J, Ignaszewski A. The prognostic importance of endothelial dysfunction and carotid atheroma burden in patients with coronary artery disease. J Am Coll Cardiol 2003; 42: 1037-1043.

14 Johnsen SH, Mathiesen EB, Joakimsen O, Joakimsen O, Stensland E, Wilsgaard T, Løchen ML, Njølstad I, Arnesen E. Carotid atherosclerosis is a stronger predictor of myocardial infarction in women than in men: a 6 -year follow-up study of 6226 persons: the Tromsø Study. Stroke 2007; 38: 2873-2880.

15 Simon A, Megnien JL, Chironi G. The value of carotid intima-media thickness for predicting cardiovascular risk. Arterioscler Thromb Vasc Biol 2010; 30: 182-185.

16 Ershova AI, Balakhonova TV, Meshkov AN, Rozhkova TA, Boytsov SA. Ultrasound markers that describe plaques are more sensitive than mean intima-media thickness in patients with familial hypercholesterolemia. Ultrasound Med Biol 2012; 38: 417-422.

17 Terai M, Ohishi M, Ito N, Takagi T, Tatara Y, Kaibe M, Komai N, Rakugi H, Ogihara T. Comparison of arterial functional evaluations as a predictor of cardiovascular events in hypertensive patients: the Non-Invasive Atherosclerotic Evaluation in Hypertension (NOAH) study. Hypertens Res 2008; 31: 1135-1145.

18 Matsuo S, Imai E, Horio M, Yasuda Y, Tomita K, Nitta K, Yamagata K, Tomino Y, Yokoyama $\mathrm{H}$, Hishida A. Revised equations for estimated GFR from serum creatinine in Japan. Am J Kidney Dis 2009; 53: 982-992.

19 Sakaguchi M, Kitagawa K, Nagai Y, Yamagami H, Kondo K, Matsushita K, Oku N, Hougaku H, Ohtsuki T, Masuyama T, Matsumoto M, Hori M. Equivalence of plaque score and intima-media thickness of carotid ultrasonography for predicting severe coronary artery lesion. Ultrasound Med Biol 2003; 29: 367-371.
20 Mancia G, De Backer G, Dominiczak A, Cifkova R, Fagard R, Germano G, Grassi G, Heagerty AM, Kjeldsen SE, Laurent S, Narkiewicz K, Ruilope L, Rynkiewicz A, Schmieder RE, Boudier HA, Zanchetti A, Vahanian A, Camm J, De Caterina R, Dean V, Dickstein K, Filippatos G, Funck-Brentano C, Hellemans I, Kristensen SD, McGregor K, Sechtem U, Silber S, Tendera M, Widimsky P, Zamorano JL, Erdine S, Kiowski W, Agabiti-Rosei E, Ambrosioni E, Lindholm LH, Viigimaa M, Adamopoulos S, Agabiti-Rosei E, Ambrosioni E, Bertomeu V, Clement D, Erdine S, Farsang C, Gaita D, Lip G, Mallion JM, Manolis AJ, Nilsson PM, O’Brien E, Ponikowski P, Redon J, Ruschitzka F, Tamargo J, van Zwieten P, Waeber B, Williams B. Management of arterial hypertension of the European Society of Hypertension; European Society of Cardiology. 2007 Guidelines for the Management of Arterial Hypertension: The Task Force for the Management of Arterial Hypertension of the European Society of Hypertension (ESH) and of the European Society of Cardiology (ESC). J Hypertens 2007; 25: 1105-1187.

21 Komai N, Ohishi M, Morishita R, Moriguchi A, Kaibe M, Matsumoto K, Rakugi H, Higaki J, Ogihara T. Serum hepatocyte growth factor concentration is correlated with the forearm vasodilator response in hypertensive patients. Am J Hypertens 2002; 15: 499-506.

22 Folkow B. Structure and function of the arteries in hypertension. Am Heart J 1987; 114: 938-948.

23 Franklin SS, Gustin W 4th, Wong ND, Larson MG, Weber MA, Kannel WB, Levy D. Hemodynamic patterns of age-related changes in blood pressure. The Framingham Heart Study. Circulation 1997; 96: 308-315.

24 O'Rourke M, Frohlich ED. Pulse pressure: Is this a clinically useful risk factor? Hypertension 1999; 34: 372.

25 Franklin SS, Khan SA, Wong ND, Larson MG, Levy D. Is pulse pressure useful in predicting risk for coronary heart disease? The Framingham heart study. Circulation 1999; 100: 354-360.

26 Staessen JA, Thijs L, O'Brien ET, Bulpitt CJ, de Leeuw PW, Fagard RH, Nachev C, Palatini P, Parati G, Tuomilehto J, Webster J, Safar ME. Ambulatory pulse pressure as predictor of outcome in older patients with systolic hypertension. Am J Hypertens 2002; 15: 835-843.

27 Najjar SS, Scuteri A, Shetty V, Wright JG, Muller DC, Fleg JL, Spurgeon HP, Ferrucci L, Lakatta EG. Pulse wave velocity is an independent predictor of the longitudinal increase in systolic blood pressure and of incident hypertension in the Baltimore Longitudinal Study of Aging. J Am Coll Cardiol 2008; 51: 1377-1383.

28 Shrestha I, Takahashi T, Nomura E, Ohtsuki T, Ohshita T, Ueno H, Kohriyama T, Matsumoto M. Association between central systolic blood pressure, white matter lesions in cerebral MRI and carotid atherosclerosis. Hypertens Res 2009; 32: 869-874.

29 Manolio TA, Burke GL, O'Leary DH, Evans G, Beauchamp N, Knepper L, Ward B. Relationships of cerebral MRI findings to ultrasonographic carotid atherosclerosis in older adults: the Cardiovascular Health Study. CHS Collaborative Research Group. Arterioscler Thromb Vasc Biol 1999; 19: 356-365.

30 Lee EJ, Kim HJ, Bae JM, Kim JC, Han HJ, Park CS, Park NH, Kim MS, Ryu JA. Relevance of common carotid intima-media thickness and carotid plaque as risk factors for ischemic stroke in patients with type 2 diabetes mellitus. Am J Neuroradiol 2007; 28: 916-919.

31 Libby P. Inflammation in atherosclerosis. Nature 2002; 450: 868-874.

32 Al-Shali K, House AA, Hanley AJ, Khan HM, Harris SB, Mamakeesick M, Zinman B, Fenster A, Spence JD, Hegele RA. Differences between carotid wall morphological phenotypes measured by ultrasound in one, two and three dimensions. Atherosclerosis 2005; 178: 319-325.

33 Roman M, Naqvi T, Gardin J, Gerhard-Herman M, Jaff M, Mohler E. Clinical application of noninvasive vascular ultrasound in cardiovascular risk stratification: a report from the American Society of Echocardiography and the Society for Vascular Medicine and Biology, Vasc Med 2006; 11: 201-211.

34 Ogihara T, Nakao K, Fukui T, Fukiyama K, Ueshima K, Oba K, Sato T, Saruta TCandesartan Antihypertensive Survival Evaluation in Japan Trial Group. Effects of candesartan compared with amlodipine in hypertensive patients with high cardiovascular risks: candesartan antihypertensive survival evaluation in Japan trial. Hypertension 2008; 51: 393-398.

35 Munakata M, Nunokawa T, Yoshinaga K, Toyota TJ-TOPP Study Group. Brachial-ankle pulse wave velocity is an independent risk factor for microalbuminuria in patients with essential hypertension-a Japanese trial on the prognostic implication of pulse wave velocity (J-TOPP). Hypertens Res 2006; 29: 515-521. 